\title{
The Cultural Recreation of the Traditional Working and Living Appliances in Tibetan and Qiang Culture
}

\author{
Cen Hua ${ }^{1}$, Ma Chuandong ${ }^{2, *}$ \\ ${ }^{1}$ College of Engineering, Sichuan Normal University, Chengdu, China \\ ${ }^{2}$ College of Fundamental Education, Sichuan Normal University, Chengdu, China \\ *E-mail address: machuandong2006@163.com
}

\begin{abstract}
Confronting the contradiction of the global trend of cultural homogenization and the appeals for the independence of national culture, this paper put forwards the new design concept of "Green Humanity". Guided by the "green humanity" philosophy, our research on the living and working appliances typical of Tibetan and Qiang people, and on the practice of the localization strategy of cultural recreation of Tibetan and Qiang culture would make our national culture more and more prosperous. It is a conscious measure to make use of design strategy, but for the local people who use the improved appliances, the process of "using" would be an unconscious heritage of culture, a process of evolution in a quiet way more beneficial to the natural heritage of culture.
\end{abstract}

Keywords: traditional working and living appliances; green humanity; cultural recreation

\section{LITERATURE REVIEW}

At present, the relative researches on the cultural recreation of the traditional working and living appliances in Tibetan and Qiang culture involves three aspects: ecological design (aiming at the concept of green humanity), the formation and the current situation of the regional culture of Tibetan and Qiang nationalities, and the measures for protection and cultural heritage.

1) Researches on ecological design. Experts hold the idea that ecological design, also green design, is the highest degree of industrial design. Directed by ecological philosophy, the designers make use of ecological thinking and put the design of the objects into the Human -Machine (products) - Environment system, which can satisfy the need of human being and at the same time designers lay emphasis on the ecology protection and the rules for sustainable development in order to protect natural value and realize social value to promote the coprosperity of human and nature (Xu Xihua, 1999).

2) Researches on the formation and the current situation of the regional culture of Tibetan and Qiang nationalities. Most experts agree that the folk architectures, costumes and productions in Tibetan and Qiang cultures are the outcomes of the Tibetan and Qiang nationalities when they were acclimatizing themselves to the nature and adjusting their measures to the local 
conditions in the long past (Li Wanbin, 2005). The ways to make use of natural sources usually have a great impact on the reservation and heritage of minority cultures, which is especially prominent in the northwest regions of Sichuan province inhabited by ethnic groups. Due to the influence of modern civilization and the Han nationality culture on the minority regions and the different degrees of the influence of the national religions on the local people, the national characteristics of the local villages are losing at varying degrees (Liu Bin, 2005). After the Wenchuan earthquake in 2008, many traditional architectures of Qiang nationality were seriously damaged (Lu Weizhong, 2011). How to rescue and protect the traditional architectures and how to develop the traditional cultures of Qiang and Baima Tibetan nationalities become the urgent tasks. But in the process of development, some developers make the damaged ecological environment even more fragile because they are anxious to achieve quick success and get instant benefits. The local culture typical of minorities has been far away from the traditional culture traits (Guang Ming Online, 2012).

3) Researches on the measures to protect and reserve the Tibetan and Qiang cultures: mainly on the development of tourism industry, reservation of the folk customs villages and ecological migration (include Tibetan and Qiang architectures). Researchers agree that it is one of the best choices to make use of local architecture to develop cultural tourism industry typical of Qiang nationality in Beichuan (Lu Weizhong, 2011). It is one of the most important measures to delay the traditional folk custom variation if we reserve or restore the folk customs villages in the remote regions inhabited by Tibetan and Qiang minorities (Liu Bo, 2008). Attention should be paid to the folk custom base construction, folk custom villages and museums construction so as to consolidate the carrier for the serial researches on folk culture, reserve the folk culture research ontology (Li Wanbin, 2005), and construct ecological resources skirts while promoting ecological migration urbanization (Qing Xiangyang, 2006).

To sum up, the research objects of green design at present focus on man and nature at present, but few on the direction and position function of the regional culture to industry design from the viewing angle of "Green Culture" under the circumstance of cultural convergence. The measures to the protection and heritage of the regional culture of Tibetan and Qiang nationalities are mainly on the development of tourism industry, the reservation of folk custom villages and ecological migration include Tibetan and Qiang architectures. Although all these research achievements can be used for references in the recreation of the regional culture, the authors of this paper think the relative researches are mostly on the protection of natural environment, economy construction and national fusion and they ignore a very important factor which influence national culture inheritance and development: the national culture inheritance should be helpful to the traditional ways of production and living.

The development of national tourism helps to spread national culture, but if the ways of living of the Tibetan and Qiang people have changed, and if their national characters and culture can not be inherited through their ways of production and living, the characteristic "origin" can not be persistent, then the inheritance and development of culture could only be meaningless image, because the sustainable development of culture need its original "parents".

\section{THE MEANINGS OF THE RESEARCH}

1) "What man needs is influenced by it cultural environment and culture is the spiritual support to man's existence. The behavioral pattern of human being ( ways of living and working ) varies in different culture and so are their needs. For example, the kitchen utensils in our traditional culture are only a knife and a pair of chopsticks." (Li Leshan, 2005). We clearly 
know that, judging by the researches on the cause of the formation of Tibetan and Qiang culture, the formation of the traditional culture is based on its relevant ways of living and working, therefore, our research will surely focus on the improvement of the production and living appliances with Tibetan and Qiang cultural characteristics, which are more effective to the benefit of living environment. Localization is the original base for the recreation of cultural productivity. Only this kind of appliances used by the local people can be recreated. The process of "using" is the process of gradual cultural penetration. As everyone knows that the environmental house furnishing greatly influence people's value, ways of living and aesthetic consciousness.

2) This paper puts forward the "Green Humanity" as the design philosophy to direct the design of the working and living appliances for Tibetan and Qiang people so as to fulfill the cultural recreation. Green in the concept "Green Humanity" has two meanings: first, it refers in particular to the purifying of culture. What is culture? Culture refers to the ideas, beliefs, and customs that are shared and accepted by people in a society, defined in Longman Dictionary of Contemporary English (Della Summers, 2004). In order to maintain its peculiarity and lessen the impact of the modernization to the Tibetan and Qiang culture, our research and design have to be rooted in the local culture and customs and avoid using the popular design language and assessment criteria. "Difference" is the progress of gene (Gao Zhanxiang, 2007). If the box-shaped gas stoves and the electrical blenders take the place of the Guozhuang (In Chinese, Guo originally referred to stoves or pots for cooking, and later Guozhuang developed into a kind of folk dance of Tibetan people. After a day's hard working, a group of Tibetans would dance circling a fire with a pot on it and enjoy themselves.) and stone mills, one of important props in Tibetan folk dance, the production efficiency is improved, but life becomes dull. This kind of "Bringism" would certainly be a shock to the national culture. Second, it refers to the improved products which can not only protect environment but also improve the living condition of the local people.

"Humanity", defined in Ci Hai (a large-scale Chinese dictionary), means, "various cultural phenomenon in human society". "Green Humanity" advocates the man - oriented " non-polluted" cultural phenomenon.

Therefore, the green humanity design research on the working and living appliances in Tibetan and Qiang region should be like this: the design philosophy for the appliances (both for its practical and aesthetic functions) should be in accordance with the unique emotion and beliefs of Tibetan and Qiang nationalities.

Only the improved products with the folk culture gene of Tibetan and Qiang people can keep our distinctive culture in the process of the recreation of traditional culture. The authors of this paper have already finished the research on the improvement of Guozhuang and Qiang architectures.

The improved Guozhuang not only remains the "Life fire" of Tibetan and Qiang people, but also non-polluted compared with the traditional ones. Compared to the "still" patterns in "museum", the "dynamic" recreation is more vigorous.

\section{RESEARCH PROCEDURE}

Our research involves three steps: first, we will make research on the traditional modes of working and living of Tibetan and Qiang people in the northwest of Sichuan province by consulting relevant document literature in order to have a clear idea about the folk customs; second, based on the field research we have done before, we will make further research on 
some selected point; third, we will make innovation on their daily-used working and living appliances.

1) We aim at exploiting the internal relation among regional culture, product design and design culture form. We start from the research on the daily-used working and living appliances, and make clear their construction, function and cultural background in order to make innovation in their material function and mental function. We hope that the innovative appliances would not only greatly improve the working and living efficiency of the local people, but also at the same time the molding style would be more appropriate in their aesthetic awareness in Tibetan and Qiang culture. The Tibetan and Qiang people could really enjoy the happiness brought by the cultural recreation in working. For example, Guozhuang, the core of Chinese fireplace culture, is now one of the most important living appliances typical of Tibetan and Qiang culture, which is both practical and entertaining. Fire worship is the basic element in Chinese fireplace culture (Yang Fuquan, Zheng Xiaoyun,1991). But the congenital deficiency of Guozhuang, the harmful smoke and dirt produced by Guozhuang, has troubled people for centuries. Therefore, when we improve the traditional Guozhuang, we should first of all respect the Qiang culture, still taking wood, stone or metal as the construction materials so as to keep the original characteristics of Qiang nationality in its color and modeling design style, and then try to solve the problem of indoor air circulation and smoke evacuation by combining Guozhuang with the traditional caisson ceiling. In this way, the Tibetan and Qiang people' $\mathrm{s}$ admiration for "Life Fire" is maintained, while indoor environment is greatly improved.

2) In addition, the festival celebration, wedding celebration and competitive races in the villages of the minority regions are the objects of our design researches. We aim at developing the regional culture when restoring the economic construction after the Wenchuan Earthquake. In Qiang's tradition, in the fifth day of Chinese Lunar New Year, Qiang people would celebrate the "Eqie" festival, the Hunting Festival. It is a day for men when they offer sacrifices to Abasi (God), thanking God for giving beasts to the Qiang people. After the worship ceremony, a hunting race would begin. Qiang people believe that the more animals a man gets, the happier his family would be in the coming year. Hong Muji, a crack shot in Qiang village, realizing that his shooting might result in the wild animals dying out, moved to the forest and lived in a cave, confessing. The Qiang people also realized the cruel fact and no longer killed wild animals. Later, people would shoot "Momo" (steamed bun, a traditional food in China) in the "Eqie" festival instead of animals to keep the tradition on, and at the same time, the festival reminds people that human being should respect nature to keep the harmonious relationship between man and nature. Based on this, we can design some tourist souvenirs similar to the shooting toys to keep the tradition.

3) We can also make extension research on teaching modes, guided by the concept of green humanity design. First, popularizing Tibetan and Qiang languages. “ ... which would be very important for promoting the political, economic, and cultural development and progress in the Qiang region." (Wu Dingchu, Zhu Chengli, 2007) Second, there would be more breakthroughs for the college students in their study if they take part in the protection of Tibetan and Qiang culture. For example, students majoring in music can compose the life scene of a Qiang girl striking boiled potatoes in a stone nest with a wooden mallet in their dance to popularize the folk customs. Students majoring industrial design can borrow the experience of "Beijing Cloth Shoes in old style" to popularize the delicate embroidered shoes of Qiang people. Students majoring in literature can present the folk religion culture by reproducing folklore... . 


\section{CONCLUSION}

Based on the consensus of protecting environment in the world, "Green design" comes into being, but the cultural hegemony results in various culture corrosion in many parts of the world. The underdeveloped countries and regions are actively looking for effective ways to protects their national cultures. This paper put forwards the new design concept "Green Humanity" confronting the contradiction of the global trend of cultural homogenization and the appeals for the independence of national culture. Guided by the "green humanity" philosophy, our research on the living and working applances typical of Tibetan and Qiang people, and on the practice of the localization strategy of cultural recreation of Titetan and Qiang culture would make our national culture more and more prosperous. It is a concious measure to make use of design strategy, but for the local people who use the improved appliances, the process of "using" would be an unconcious inheritage of culture, a process of evolution in a quiet way, which would be more beneficial to the natural inheritage of culture. "Design" and "use" contribute to the cultural recreation.

Product design for man (Tibetan and Qiang people) - material (appliances) environment (the natural and social environments in the Tibetan and Qiang minority regions in the northwest of Sichuan Province) is difficult problem. How to balance the traditional culture characteristics and modern culture characteristics would be our research focus in the future.

\section{References}

[1] Della Summers, Longman Dictionary of Contemporary English, Foreign Language English and Research Press, Beijing, 2004.

[2] Li Leshan, Industrial Design Psychology, Higher Education Press, Beijing, 2005.

[3] Gao Zhanxiang, Cultural Power, Peking University Press, Beijing, 2007.

[4] Guang Ming Online, 2012.

[5] Yang Fuquan, Zheng Xiaoyun, Recorded Fireplace Culture, Yunnan People's Publishing House, Kunming, 1991.

[6] Wu Dingchu, Zhu Chengli, Educational Development of Qiang People in One Hundre Years, The Central Literature Press, Beijing, 2007. 